\title{
New eyes on old drugs
}

A unique example of open source collaboration has been struck between Pfizer and Washington University in St. Louis. New York-based Pfizer agreed, in May, to provide university researchers with information on more than 500 drug candidates to give them the opportunity to identify new uses for these compounds.

The agreement entitles Washington University to $\$ 22.5$ million over five years and access to proprietary data, which are not normally released to university groups. "By allowing others to consider the additional use of our compounds, we hope to identify new opportunities for truly unmet medical needs," says Don Frail, chief scientific officer of Pfizer's indications discovery unit.

The advantage for the academic researchers is that Pfizer's compounds have been extensively studied and their mechanisms are well understood, shaving off time needed for evaluation. In the new collaboration, when the researchers find a promising new application for a compound, they can propose a research project to Pfizer. The university will have the opportunity to negotiate the commercialization terms for its discoveries. Stephen Strauss Toronto

format is another problem. Managing the complexity of collaborations that occur when large numbers of institutions and individuals collaborate creates another twist in the road toward open participation. This is particularly worrisome in the light of a recent counterintuitive finding by Jonathon Cummings of Duke University, who studied 491 National Science Foundation-funded research collaborations. He found more can turn into less if the project is not carefully managed. "Our study found that projects with more collaborating institutions, on average, were less likely to have published papers and patent applications compared with projects with fewer collaborating institutions," says Cummings.

Another issue is that although companies theoretically give all their data to open collaboration, "often only select data are permitted to be shared," says Bruno Boutouyrie, who heads up the F. Hoffmann-La Roche clinical pharmacology central nervous system division, and who was one of the paper's co-authors. This leads to the general argument that open source collaboration is probably best arrived at when all parties agree ahead of time what will and won't be publicly available.

But, says Boutouyrie, "controlling the direction of research in a network may be the most important problem." That is to say: who decides a given line of research is exhausted and one must just move on.

Such issues may challenge open collaborations between academia and industry. Thus, whereas industry researchers are used to axing projects if a target turns out to be undruggable or a lead series has unacceptable toxicities or equivocal efficacy, this kind of abrupt stop to a research program creates tensions with university investigators whose graduate students' funding may be cut in the midst of a $\mathrm{PhD}$. To deal with this "you will have to get some transitional funding arrangement so an institution is not disadvantaged internally," says Colin Dollery,

\section{IN their words}

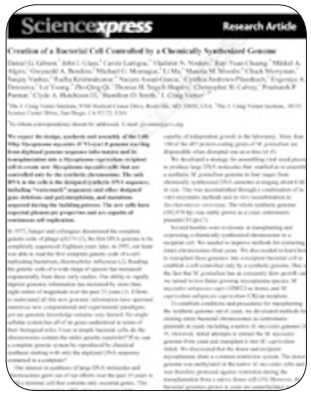

cloning a genome with 1.08 million base pairs might seem to be a trivial extension of the 1984 synthesis of a gene containing about 300 base pairs... This paper shows that it was not." Steven Benner, Foundation for Applied Molecular Evolution, Gainesville, Florida, (Nature, 27 May 2010)
"There's no doubt in my mind that this is a major achievement. But is it artificial life? Of course not." Steen Rasmussen, a professor of physics at the University of Southern Denmark (New York Times, 31 May 2010).

\section{"Synthesizing and}

"An interesting result." The Vatican ( $C N N$, May 22 2010)

"I hope very much these patents won't be accepted because they would bring genetic engineering under the control of the J Craig Venter Institute. They would have a monopoly on a whole range of techniques." John Sulston, University of Manchester (BBC News, 24 May, 2010)

"This milestone and many like it should be celebrated. But has the JCVI created 'new life' and tested vitalism? Not really...Printing out a copy of an ancient text isn't the same as understanding the language." George Church, Harvard (Nature 465, 422-424, 2010)

“A marvelous advance, but it doesn't immediately open up or enable new studies for the broad community." James Collins, Boston University (New Scientist, 26 May 2010)

IN brief

\section{Genetic testing clamp down}

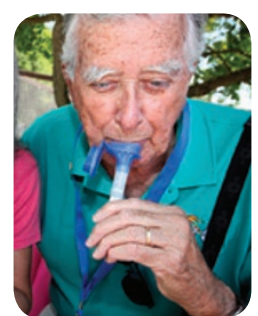

Consumer takes a 23andMe genetic test.
The US Food and Drug Administration (FDA) has told five genetic test manufacturers that their products need the agency's blessing before they can be sold to consumers. On June 10th, the agency sent letters to Illumina, of San Diego, Pathway

Genomics also of San Diego, NaviGenics, 23andMe and deCODE Genetics, of Reykjavik, Iceland, explaining that their genetic tests are considered medical devices and must be approved. The FDA had no specific plans to regulate these direct-to-consumer tests until recently when Pathway Genomics announced its intention to market a kit at pharmacy chain Walgreens. Customers would buy the Pathway Genomics' Insight Saliva Collection Kit at most of Walgreen's 7,500 stores for $\$ 20$ to $\$ 30$ and send their saliva sample to Pathway to undergo what the company terms "comprehensive genotyping." They could then order individualized Genetic Insight Reports for Drug Response (\$79), Pre-Pregnancy Planning (\$179), Health Conditions (\$179) or a combination of all three (\$249). The FDA quickly sent a letter to Pathway stating that agency staffers were "unable to identify any Food and Drug Administration clearance or approval number," for the kits, a clear indication that they expected to find that. Pathway responded that their laboratory is Clinical Laboratory Improvement Amendments (CLIA)approved, which they believed sufficient. That little scuffle prompted Walgreens to announce that it would postpone offering the kits "until we have further clarity on this matter." The furor even caught the interest of Congress. The House Energy and Commerce Committee requested information about their tests from Pathway, 23 and Me, of Mountain View, and Navigenics of Foster City, both in California. After many months of regulatory uncertainty, the FDA's stance is welcome (Nat. Biotech, 27, 875, 2009). All of these companies have been selling such services from their websites for more than a year and will be allowed to continue. But it appears that the agency will no longer be satisfied with just CLIA certification for genotyping facilities, which is how most of these firms operate. According to an e-mail from Dick Thompson of the FDA Office of Public Affairs, "The agency has been meeting with several companies to understand their claims and business models." The FDA will hold a public meeting on July 19 and 20 to discuss how the agency will oversee laboratory-developed tests.

Malorye Allison 